\title{
CONTRA EL GOBIERNO DE LOS JUECES
}

\section{Jeremy Waldron}

Buenos Aires: Siglo XXI, 2018, 254 páginas

Jeremy Waldron, neozelandés y ampliamente reconocido en el plano académico internacional por sus contribuciones al derecho constitucional y a la teoría política, realiza una elegante crítica sobre el control judicial de la constitucionalidad. Lo que no es sorprendente viniendo de Waldron, que a fin de cuentas es, en sus palabras, "enemigo declarado del control judicial" (p. 45). Su obra constituye un aporte significativo al tipo de posturas que consideran que el poder de los jueces no necesariamente debe ser aceptado a la hora de decidir qué es o no constitucional en una democracia. Tener la última palabra en la interpretación de la constitución del Estado y revisar las leyes ${ }^{1}$ emanadas de un poder netamente democrático como el Parlamento, cuanto menos, genera sospecha.

La obra se estructura en cinco partes, cuyo objeto es criticar el control judicial fuerte ${ }^{2}$ de las leyes, en el cual existe una excesiva intromisión judicial en la actividad política parlamentaria y argumentar por qué se deben buscar otras alternativas institucionales cuando se interpretan las constituciones.

En la primera parte de la obra se empieza analizando el significado de una palabra determinante, como lo es "constitucionalismo". Palabra que, sin lugar a dudas, es muy relevante en el derecho constitucional y la teoría política. Así, critica la idea de constitucionalismo para aproximarse al sentido que puede tener como concepto. Describe cómo "constitucionalismo" puede usarse de distintas maneras en el ámbito académico, incluso, haciendo énfasis en el componente "ismo" que contiene la idea, ya que existen otras palabras como liberalismo o socialismo, es decir, interpretándose como una suerte de ideología, lo cual resulta interesante debido a que no suele ser planteado el concepto de esa manera.

\footnotetext{
1 No se incluye en el objeto de la obra la revisión judicial sobre actos jurídicos provenientes del Ejecutivo o administración.

2 No se incluye en su crítica el control judicial débil.
} 
Se realiza un repaso de los fundamentos que se suelen señalar del constitucionalismo, desmenuzando los diversos sentidos que desde las revoluciones liberales del siglo XVIII se le han atribuido. Sobremanera, resalta el sentido de control que implica el constitucionalismo, lo cual ha sido una nota esencial y siempre reafirmada por los grandes pensadores. Controlar el poder, en efecto, es una propiedad del constitucionalismo que suele ser alegada por los constitucionalistas cuando se invoca a debate esa palabra. Diseñar límites al poder público es el telos o "razón de ser del constitucionalismo" (Sartori, 2005, p. 213). Basta indicar que constitucionalismo, en su origen, surge como oposición al absolutismo del poder que tiende a abusar y corromper. En esencia, el descontrol del poder es lo que suscitó el constitucionalismo como necesidad institucional para garantizar los derechos fundamentales. Tal rasgo de control resulta indisociable de la definición de "constitucionalismo", pese a denominaciones que ahora se puedan encontrar de "constitucionalismo autoritario". ${ }^{3}$

En la segunda parte, la obra se adentra en los argumentos contra el control judicial fuerte y que sostienen la afirmación de que es "inapropiado como última instancia dentro del proceso de toma de decisiones en una sociedad libre y democrática" (p. 56). La vulnerabilidad del control judicial fuerte se puede destacar, según nuestra interpretación, de la ilegitimidad democrática sobre la cual descansa, que privilegia el voto mayoritario de un pequeño grupo de jueces no elegidos democráticamente y que no les rinden cuentas a los depositarios de la soberanía popular.

El control judicial que se critica es un control matizado sobre ciertas condiciones sociales: 1) instituciones democráticas, cuyo poder legislativo sea elegido mediante sufragio universal; 2) instituciones judiciales, comprometidas con el mantenimiento del Estado de derecho; 3) compromiso de la sociedad y los agentes públicos con la idea de los derechos individuales y de las minorías; y 4) desacuerdos legítimos sobre los derechos de parte de la sociedad. Con base en estas condiciones, se aborda el aspecto decisorio institucional del control judicial.

Asimismo, se consideran también las virtudes de la decisión tomada por el poder legislativo y los factores clave que influyen en el razonamiento para crear una ley. Especialmente se realiza una comparación entre el sistema constitucional de los Estados Unidos y el sistema del Reino Unido. Por un lado, se destaca la labor activista de la Corte Suprema norteamericana y, por el otro, la

Ver Tushnet (2015). 
supremacía legislativa del Parlamento en el Reino Unido. Pero ¿por qué un ciudadano debe aceptar la decisión de una corte o de un parlamento? En el caso legislativo, la aceptación de la decisión es considerablemente superior en valores democráticos al caso judicial. Esto es un rasgo trascendental en el momento de aceptar una decisión desde la perspectiva de la legitimidad democrática. Los legisladores rinden cuentas periódicamente ante los electores, situación que no ocurre por parte de los jueces.

Por si el argumento no fuera suficiente, es menester destacar que si bien se argumenta que los jueces que conforman una Corte toman decisiones con base en argumentos, algo así como una aristocracia de la "razón", como bien señala el autor, "en definitiva todo se reduce a contar cabezas" porque, por ejemplo "en la Corte Suprema de los Estados Unidos, cinco votos vencen a cuatro, independientemente de los argumentos esgrimidos por los jueces" (p. 106). Este es un factor clave para entender la crítica que se propone, ya que los jueces deciden bajo el criterio del mayoritarismo. De manera que la famosa tiranía de la mayoría que suele argumentarse para sustentar los poderes activistas de los jueces que limitan la labor legislativa se vuelve muy dudosa. En efecto, los tribunales también pueden actuar de manera tiránica. A veces, hasta más tiránicos que un parlamento. ${ }^{4}$

El tercer capítulo se refiere a la "supremacía judicial", que se define como "la tendencia de cualquier arreglo institucional que permite que esas cuestiones vitales [esto es, cuestiones que afectan a toda la población] y divisivas sean resueltas por tribunales" (p. 132). Tal supremacía judicial se establece en sistemas en los que persiste un control judicial fuerte. Asimismo, la idea de supremacía judicial se relaciona con la idea de soberanía judicial. Waldron, cuando trata este punto, refiere elementos fundamentales acerca de la soberanía y el poder constituyente. Principalmente, resalta que los tribunales con su control judicial pueden atribuirse el lugar supremo del poder constituyente cuando consideran solamente su propia idea de constitución, como una especie de propietario, sin considerar las demás ramas del poder o "sociedad abierta de intérpretes constitucionales", 5 a los cuales sus decisiones afectan. Es decir, el monopolio de la

4 Por ejemplo, el caso de la Sala Constitucional del Tribunal Supremo de Justicia de Venezuela es un supuesto muy pertinente para explicar cuán tiranos pueden ser los jueces (esto, pese a que escapa de las condiciones sociales sobre las cuales el autor fundamenta su crítica). En Venezuela, la Sala Constitucional desconoció al Parlamento como hacedor de la ley, vaciando de contenido la mayor parte de sus competencias para herir gravemente la democracia y la Constitución.

Ver Häberle (2008). 
interpretación de la constitución es, sin dudas, una situación alarmante en el diseño institucional de un ambiente democrático.

La cuarta parte se refiere a las razones del porqué en los tribunales deciden "mayorías exiguas". Es casi una costumbre universal que los tribunales colegiados deban decidir mediante el criterio de las mayorías en cualquier tipo de asunto, trátese de derecho público o derecho privado. Entonces, los defensores del control judicial alegan que se oponen al mayoritarismo, pero es un argumento de escasa fuerza, desenmascarado por el autor: en la práctica, las decisiones judiciales dependen de un "conteo de cabezas" (p. 158). Así, quienes están a favor del control judicial "[e]n realidad se oponen al mayoritarismo democrático, no al mayoritarismo como tal” (p. 155). En otras palabras, el control judicial tiene un problema o dificultad contrademocrática más que lo que Bickel (1986) en su momento calificó como "contramayoritaria".

Ahora bien, habiendo entendido que los jueces deciden también bajo el criterio de la mayoría, con acuerdos y desacuerdos, por consiguiente, también existe deliberación. Tratando la génesis del tipo de mayoría que generalmente se requiere para tomar decisiones en un órgano judicial colegiado, se indica que es un tipo de mayoría "exigua”. Eso, por cuanto, generalmente, la mayoría requerida no es calificada o por unanimidad para dirimir los desacuerdos. Este es un elemento interesante, ya que ampliar el tipo de mayoría requerida en un tribunal para tomar una decisión podría hacer que no se tome a la ligera la dignidad de la ley. Asimismo, los desacuerdos naturales de todo ser racional exigirían mayor calidad argumentativa para ser dirimidos.

Finalmente, en la quinta parte, el autor ofrece "modelos de diálogo entre jueces y legisladores", algo parecido a una alternativa sobre cómo lidiar con el ego judicial y legislativo. Sobre todo el primero, que es objeto de su crítica. Se destacan seis posibilidades de diálogo entre jueces y legisladores dentro de múltiples supuestos. Los modelos de diálogo que se analizan son: 1) modelo Lord Devlin; 2) modelo de diálogo paralelo; 3) modelo neozelandés; 4) modelo británico; 5) modelo canadiense; y 6) el camino que no se tomó en City of Boerne c/Flores. Acerca de todos estos modelos se resaltan los diseños institucionales empleados para cada país y en lo que contribuyen al sentido del diálogo.

De acuerdo con el análisis de Waldron, en aquellos sistemas en los que existe supremacía judicial tiende a haber menos diálogo que en los sistemas en los que hay supremacía legislativa. Los jueces tienen más probabilidad de ser escuchados en un sistema en el que el parlamento sea soberano que la probabilidad que tienen los legisladores de ser escuchados en un sistema en el que los jueces 
tengan la última palabra. Estas son las críticas que realiza el autor en contra del control judicial fuerte o gobierno de los jueces.

Cada palabra escrita en esta obra es merecedora de una seria reflexión. La mayor parte de los sistemas constitucionales en América Latina son preponderantes a tener un control judicial fuerte, en el cual los jueces tienen la última palabra sobre cuestiones trascendentales para la sociedad, como el aborto, la eutanasia o el matrimonio entre personas del mismo sexo. Considerar posiciones como la de Waldron al momento de reformar o crear nuevas constituciones en la región es una forma de enriquecer el debate constitucional. Especialmente enriquecedor para el constitucionalismo de la región sería pensar sobre diseños institucionales que contribuyan a democratizar más el ejercicio del poder. Los cambios constitucionales recientes se han preocupado más por reconocer ampliamente los derechos que por diseñar nuevas instituciones. ${ }^{6}$ Por tanto, la obra del autor constituye una crítica respetable sobre el control judicial fuerte de las leyes, cuyo significado no debe pasar desapercibido en un momento de reflexión constitucional.

\section{Angello Javier Peña Barrios}

Universidad de Los Andes

angellojavierpb@gmail.com

\section{Bibliografía}

Bickel, A. (1986). The Least Dangerous Branch (2 ${ }^{\mathrm{a}}$ ed.). Yale University Press.

Gargarella, R. (2013). Latin American Constitutionalism, 1810-2010. The Engine Room of the Constitution. Oxford University Press.

Häberle, P. (2008). La sociedad abierta de los intérpretes constitucionales: una contribución para la interpretación pluralista y 'procesal' de la constitución. Academia, Revista sobre enseñanza del Derecho, 6(11), 29-61.

Sartori, G. (2005). Ingeniería constitucional comparada. Fondo de Cultura Económica.

Tushnet, M. (2015). Authoritarian Constitutionalism. Cornell Law Review, 100(391), 393-460.

Ver Gargarella (2013). 
